\title{
INVESTIGATION OF RELATIONSHIP BETWEEN MULTIPLE INTELLIGENCES OF HIGHER DEGREE STUDENTS ON ACADEMIC PERFORMANCE IN THE UNIVERSITY OF IBADAN
}

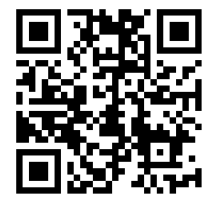

\author{
Ezekiel Olusegun Babatunde ${ }^{1}{ }^{\mathbb{a}}$, Raymond Ayoola ${ }^{2}$ \\ ${ }^{1} \mathrm{PhD}$, Institute of Education, University of Ibadan, Ibadan, Nigeria \\ ${ }^{2}$ International Centre for Educational Evaluation, University of Ibadan, Ibadan, Nigeria
}

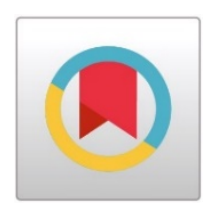

DOI: https://doi.org/10.29121/ijetmr.v7.i10.2020.755

Article Citation: Ezekiel Olusegun Babatunde, and Raymond Ayoola. (2020). INVESTIGATION OF RELATIONSHIP BETWEEN MULTIPLE INTELLIGENCES OF HIGHER DEGREE STUDENTS ON ACADEMIC PERFORMANCE IN THE UNIVERSITY OF IBADAN.

International Journal of Engineering Technologies and Management Research, 7(10), 66-72.

https://doi.org/10.29121/ijetmr.v7 .i10.2020.755

Published Date: 23 October 2020

Keywords:

Multiple Intelligences Academic Performance Higher Degree Students Logical-Mathematical Intelligence Intrapersonal Intelligence

\section{ABSTRACT}

Research into investigation of the relationship between multiple intelligences of learners and academic performance is germane. This study investigated relationship between multiple intelligences of higher degree students and academic performance. Two research questions and three hypotheses guided the correlational study. Three hundred and thirty Master degree students of the University of Ibadan who are randomly selected made the sample. Three validated instruments: Simple Multiple Intelligence Inventory developed by Gardner ( $\mathrm{r}=0.89$ ), Modified MILHDSQ $(\mathrm{r}=0.87)$ and the CGPA of students result for the two semesters was used to collect data that was analysed using descriptive and inferential statistics at 0.05 level of significance. The result reveals a very high level of multiple intelligences in the overall mean of 4.34 . Students demonstrated very much high intelligence in Logical-mathematical (Xw=4.82), interpersonal $(X w=4.57)$ and visual $(X w=4.53)$. Both logical $(8.143<0.05)$ and intrapersonal $(19.252<0.05)$ intelligences are related to academic performance. Moreover, academic performance has high correlation with Logical (0.72) and Linguistic (0.61). This shows a positive correlation between multiple intelligences and academic performance. The result provided opportunity for lecturers' awareness to observe level of multiple intelligences of students for better guidance to improve academic performance. It is recommended that teaching strategies that will accommodate multiple intelligences be designed by education stakeholders.

\section{INTRODUCTION}

Academic performance of any learner is hinged on how the potentials inherent in the learner had been developed and cultivated. No two learners can think, act, response and behave the same way and this is as a result of their individual differences which had been so designed by God and the interaction with the environment each learner is exposed to. This difference is revealed in the level of accomplishment of individual learner. Naturally, parents, teachers and all other stakeholders of education strive to develop the intellectual capabilities of children and seek to ensure that their potentialities are fully developed. It will not be out of place that the goals of education are wielded around enhancing academic performance of students, even though other numerous outcomes may also have been expected from the system. Research in recent times had shown that cognition related factors of learners

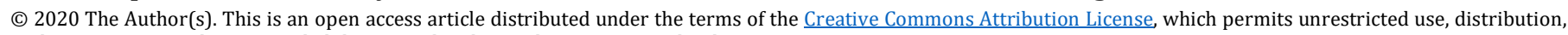
and reproduction in any medium, provided the original author and source are credited. 
Investigation of Relationship Between Multiple Intelligences of Higher Degree Students on Academic Performance in The University of Ibadan

play pivotal role behind their academic performance. However, among learner related variables of academic performance is the intelligence which is a force to reckon with and be held in high esteem.

These days, researchers have developed keen interest in the study and identification of the profile of multiple intelligences of learners belonging to various educational grades so that it could be nourished in order to optimize their academic performance. Researchers are also spending much effort to find out whether there exists any relationship between any particular type of intelligence of the learner and their level of academic performance in any particular subject. In today's world, rapid and wide developments in science, technology, communication and emergence of new views about social, political, economic, and cultural issues bring about fundamental changes in educational systems and teaching methods (Yaghoob, Hossein, Mahin, \& Fatemhi, 2016).

In order to successfully educate all students in tertiary institutions, lecturers should be aware of the students' individual differences and multiple intelligence profiles. In primary and secondary schools, logical and linguistic intelligences tend to be emphasized in teaching. Students who are more developed in other intelligence dimensions are often ignored. Therefore, identifying and knowing students' intelligence profile by the lecturer is important as it has implications for instruction.

Gardner (2006) asserted that individual differences reflect multiple intelligences of human beings; and through these intelligences, every individual attempts to explore the world. This forms the basis for the behavior exhibited by individual to show how vast they are with their immediate environment (Arnold \& Fonseca, 2004). What the multiple intelligences theory offers is not only significant from a theoretical perspective, but also has important practical implications for teaching practice. Lecturers should consider different multiple intelligences of their students during their teaching and should encourage the students to use their different intelligences in their learning (Gen, 2000). As Larsen-Freeman (2000) suggested, in an attempt to improve quality of teaching and learning, both the lecturer and student should take into account their own different multiple intelligences especially when it comes to career choice, learners' multidimensionality is expected to be celebrated and all intellectual abilities enhanced (Cohen, 2003). According to Gardner (2006), this multiple intelligences give distinction to individuals from each other because each individual possess a unique profile of intelligences of unpredictable notches.

Although, no one intelligence is considered superior to others, Gardner (2003), opined that all intelligences are required for an individual in order to participate, act purposefully and be creative in the society. In order to be successful in educating all students, lecturers should be conscious of students' individual differences and multiple intelligence profiles as multiple intelligences principles offers useful suggestions for providing a more reasonable and practical approach to instruction. Furthermore, individual intelligence can be improved through various educational ideas such as identification of weakness and strength of each learner's intelligence. In view of this fact, research into the identification and investigating the relationship between multiple intelligences of learners and their academic performance from the cradle cannot be over emphasized.

The study of multiple intelligences is at the center of multiplicity ways that learners are exposed to educational course; it also helps lecturers and learners to successfully plan for individualized tutoring. Consequently, many researchers stress the importance of identifying the profiles of learners and empowering them with the recognition of their intelligences in order to enhance and develop learning (Gurbuz \& Gurbuz 2010; Natasa 2010; Netoa, Ruiza \& Furnham 2008; Wu \& Alrabah, 2009). Thus, it seems necessary to consider their intelligences when designing teaching and learning pedagogy so as to enhance the students' learning performance. Some researchers have attributed intelligence to cause academic performance in school system (Habibollah, Abdulahi, Tengku, 2008) as they found correlation between intelligence and academic achievement. In literature, there is a school of thought that there is cause and effect relationship between the two variables. This assertion was supported by Laidra, Pullmann \& Allik (2007) who concluded that academic achievement of the students is reliant on their cognitive abilities in all grade levels.

Moreover, multiple intelligence theory according to Gardner (1999), take into cognizance individual skills and abilities for all categories of learners, be it adult, gifted, or physically challenged from diverse cultures which made this study a worthwhile venture. The theory further classified multiple intelligences along eight categories of visual/spatial, verbal/linguistic, interpersonal, intrapersonal, musical, logical-mathematical, bodily-kinesthetic and naturalistic all of which has implication for academic performance. Visual intelligence deals with learner's ability to learn best by visualizing and organizing things spatially. Learners in this group are interested in charts, graphs, maps, 
tables, illustrations, art, puzzles and anything that is eye catching. Learners' who are strong in visual-spatial intelligence are also good in visualizing things.

Verbal Linguistic intelligence deals with learner's interest in language such as, interest in speaking, writing, reading and listening. The learners' who are strong in verbal -linguistic intelligence are able to use words while they are writing and speaking. These learners' are typically very good at writing stories, memorizing information and reading. Mathematical or Logical intelligence deals with learner's ability to show an aptitude for numbers, reasoning and problem solving. Learners' who are good in logical-mathematical intelligence are also good at reasoning, recognizing patterns and logically understand and analyze problems. These individuals prefer to think conceptually about numbers, relationships and patterns (Gardner, 2006). Bodily Kinesthetic intelligence deals with learner's experience through activity like games, movement, and hands-on tasks building. Those learners' who have high bodily-kinesthetic intelligence are said to be good at body movement, performing actions and physical control. Musical Rhythmic intelligence deals with learner's musical ability. Learners' who have strong musical intelligence are good at thinking in patterns, rhythms and sound. Interpersonal intelligence deals with learner's communication styles and understanding of feelings of other people. They learn through cooperative learning in groups and they are leaders among their groups. They are good at understanding and interacting with other people. Intrapersonal intelligence deals with learners' awareness of their feelings, emotions and motivation (Gray, 2007). Naturalist intelligence deals with learner's interest towards outdoors activities, animals and field trips (Weiten, 2001). It has been observed that the traditional classroom in our tertiary institutions has not explored the efficiency of these intelligences for improved academic performance.

The inculcation of academic knowledge, skills, abilities and proficiency among the individuals is enhanced through learning and academic performance. Academic performance is one of the most outstanding indicators through which students can demonstrate their competencies and capabilities and its effectiveness by increasing learning toward improvement of performance. There are many factors that can contribute to the academic performance of individual in schools as this determines their future goals and the career opportunities that will be opened to them in the tertiary institutions. These factors include but not limited to individual differences, multiple intelligence, class participation, assignment completion, effective teaching-learning strategy, school type, order of birth in the family, family size and income among others (Nyagosia, 2011).

The size of the family is a potent factor that contributes to the academic performance of an individual. In a nuclear family, there is more attention to provide for the needs and resources of their children to make learning meaningful as less cost will be involved and enhancement of appropriate livelihood will be assured. This will contribute to growth and development. Whereas, according to Ogunsola, Osuolale, \& Ojo (2014), in a large family, meeting the needs of the children become a herculean task as most needs and requirements for the enhancement of academic performance of the children may not be guaranteed as a result of competing time for job, high cost of living and adequate monitoring on the part of the parents. All these will be detrimental to the academic performance of the child. With more children and limited income, it usually becomes difficult to meet the requirements of every child in the family.

Another factor considered in this paper is the problem of family income. Maina (2010) opined that poverty is one major obstacle within the course of academic performance. When a family per capita income is very low, catching up with the requirements of good living become difficult and this will affect diet and nutrition, health, educational and school requirements. Invariably, failure to meet the required standard of living will go a long way on the performance of the student academically as they will not be able to improve on their grades. Few studies had been carried out on multiple intelligences but there is dearth of study that evaluates the relationship between multiple intelligence profile of higher degree students and academic performance in the context of University students in Nigeria. This study was carried out to investigate the relationship of multiple intelligences on academic performance of higher degree students of University of Ibadan. Two research questions were raised and answered and three hypotheses were formulated and tested in this study. The research questions and hypotheses are:

Research Question 1: What is the profile of higher degree students multiple intelligence in the University of Ibadan?

Research Question 2: What is the level of multiple intelligences of higher degree students of the University of Ibadan?

$\mathrm{H}_{01}$ : There is no significant relationship between multiple intelligence and academic performance of higher degree students of the University of Ibadan. 
$\mathrm{H}_{02}$ : There is no significant relationship between level of multiple intelligence, profile and academic performance of higher degree student of University of Ibadan.

$\mathrm{H}_{03}$ : There is no significant correlation between multiple intelligences and academic performance of higher degree student of University of Ibadan.

\section{METHODOLOGY}

The study adopted a descriptive correlation study. Participants were drawn from among the Master's degree student in all the faculties of the University of Ibadan. Proportionate to size sampling technique was used to randomly select three hundred and thirty (330) higher degree students that participated in the study. Three validated instruments: Simple Multiple Intelligence Inventory developed by Gardner consisting of 80 items and 8 subscales was adopted as research instrument. This inventory is a standardized inventory, describing Gardner's eight multiple intelligences. There are ten items in each of the sub-scales to measure the intelligences. The instrument demonstrated strong reliability ( 0.86 the lowest one and 0.92 the highest) between the categories of the items in the sub-scales. The revalidated overall instrument yielded a Cronbach Alpha coefficient of 0.89. Multiple intelligence level of higher degree students' questionnaire (MILHDSQ) with reliability coefficient of 0.87 using a questionnaire designed on a 5-point Likert scale was used to measure the multiple intelligence level of the students. The following scales were used to interpret the level of multiple intelligences: 4.50-5.00, very much high; 3.50-4.49, very high; $2.50-3.49$, average; $1.50-2.49$, low and 1.00-1.49, very low. For the measurement of academic performance, the results of the first and second semesters were taken as students 'achievement score. Data collected was analyzed using frequency count, percentage distribution, weighted mean, and inferential statistics of chi-square set at 0.05 level of significance.

\section{RESULTS}

Table 1: Profile of the respondents by demographic data

\begin{tabular}{|c|c|c|c|}
\hline \multirow{4}{*}{ Age } & Profile & Frequency & Percentage \\
\hline \multirow{3}{*}{ Gender } & $19-21$ & 53 & 16.1 \\
\cline { 2 - 4 } & $22-24$ & 237 & 71.8 \\
\cline { 2 - 4 } & 25 and above & 40 & 12.1 \\
\hline \multirow{3}{*}{ Family monthly income } & Male & 140 & 42.4 \\
\cline { 2 - 4 } & Female & 190 & 57.6 \\
\cline { 2 - 4 } & 50,000 and below & 218 & 66.1 \\
\cline { 2 - 4 } Order of birth in family & $51,000-99,000$ & 90 & 27.3 \\
\cline { 2 - 4 } & 100,000 and above & 22 & 6.6 \\
\cline { 2 - 4 } & $1^{\text {st }}$ born & 144 & 43.6 \\
\cline { 2 - 4 } & $2^{\text {nd }}$ born & 96 & 29.1 \\
\hline
\end{tabular}

Table 1 shows the profile of the respondents. The respondents' age ranges from 19 years old and below to 25 years and above. Two-hundred and thirty-seven or $71.8 \%$ have ages ranging from $22-24$ years old while only $16.1 \%$ and $18.1 \%$ are below 19 years and 25 years and above respectively. The table also revealed a slight difference along gender as indicated by the respective percentages of 42.4 (males) and 57.6 (females). Along their monthly family income, two-hundred and eighteen or $66.1 \%$ have an income of N50,000 and below; followed by $90(27.3 \%)$ with an income of ranging from N51,000 to N99,000.00. Majority of the respondents $144(43.6 \%)$ are first born, followed by the $2^{\text {nd }}$ born $(29.1 \%)$ and last born $(27.3 \%)$ respectively. This result indicates that almost every parent will want to train their first born so as to serve as role model to other children in the family and therefore is not surprising to have this result. 
Table 2: Summary of level of Multiple Intelligence of Higher Degree Students

\begin{tabular}{|c|c|c|}
\hline Multiple Intelligences & Weighted Mean (Xw) & Descriptive Equivalent \\
\hline Visual intelligence & 4.53 & Very much high \\
\hline Linguistic intelligence & 4.32 & Very high \\
\hline Musical intelligence & 4.46 & Very high \\
\hline Interpersonal intelligence & 4.57 & Very much high \\
\hline Intrapersonal intelligence & 3.56 & Average \\
\hline Bodily-Kinesthetic intelligence & 3.88 & Average \\
\hline Logical-Mathematical intelligence & 4.82 & Very much high \\
\hline Naturalistic intelligence & 4.45 & Very high \\
\hline Overall Mean & 4.34 & Very high \\
\hline
\end{tabular}

Table 2 presented the summary of level of higher degree student multiple intelligences. From the table, higher degree students of the University of Ibadan showed very high level of multiple intelligences in the overall mean of 4.34. From the table, the students demonstrated very much high intelligence in Logical-mathematical $(\mathrm{Xw}=4.82)$, interpersonal $(\mathrm{Xw}=4.57)$ and visual $(\mathrm{Xw}=4.53)$. Moreover, the table revealed very high intelligence along Musical $(X w=4.46)$, Naturalistic $(X w=4.45)$ and Linguistic $(X w=4.32)$. It is in the area of Bodily-kinesthetic $(X w=3.88)$ and Intrapersonal $(\mathrm{Xw}=3.56)$ intelligences that the students demonstrated average intelligence. The results indicate that students learn best through logical-mathematical, interpersonal and visual. Students that display such intelligence show an aptitude for numbers, reasoning and problem solving as well as recognizing patterns and logically understand and analyze problems. In addition, they learn by understanding and interacting with other people and by visualizing and organizing things spatially. This result may not be unconnected with and justified by the vision of the University to be a world class citadel of knowledge as reflected in the admission criteria of a new student.

Table 3: Relationship between level of multiple intelligences, profile and academic performance

\begin{tabular}{|c|c|c|c|c|c|c|c|c|c|c|}
\hline \multirow{3}{*}{ INTELLIGENCES } & \multicolumn{8}{|c|}{ PROFILE } & \multirow{2}{*}{\multicolumn{2}{|c|}{ Academic Performance }} \\
\hline & \multicolumn{2}{|c|}{ Age } & \multicolumn{2}{|c|}{ Gender } & \multicolumn{2}{|c|}{ Family position } & \multicolumn{2}{|c|}{ Family Income } & & \\
\hline & $\boldsymbol{x}^{2}$ & Prob & $\mathcal{H}^{2}$ & Prob & $\mathcal{X}^{2}$ & Prob & $x^{2}$ & Prob & $x^{2}$ & Prob \\
\hline Logical & 6.980 & 0.323 & 1.094 & 0.778 & 3.601 & 0.308 & 3.428 & 0.945 & $8.143 *$ & 0.043 \\
\hline Bodily-kines & 5.545 & 0.792 & 3.394 & 0.494 & 7.908 & 0.095 & 8.228 & 0.767 & 1.273 & 0.866 \\
\hline Visual & 7.872 & 0.446 & 4.362 & 0.359 & 1.940 & 0.747 & 13.079 & 0.363 & 4.889 & 0.299 \\
\hline Musical & 6.973 & 0.540 & 6.328 & 0.176 & 1.669 & 0.796 & 16.983 & 0.150 & 4.260 & 0.372 \\
\hline Interpersonal & 10.214 & 0.250 & 4.276 & 0.370 & 1.620 & 0.805 & 10.207 & 0.598 & 2.626 & 0.622 \\
\hline Intrapersonal & 9.715 & 0.423 & 2.908 & 0.573 & 2.805 & 0.591 & 20.050 & 0.066 & $19.25^{*}$ & 0.001 \\
\hline Naturalistic & 6.280 & 0.393 & 2.700 & 0.440 & 0.562 & 0.562 & 5.413 & 0.797 & 4.640 & 0.200 \\
\hline Linguistic & $16.954^{*}$ & 0.031 & 3.916 & 0.417 & 1.436 & 0.838 & 10.703 & 0.555 & 2.005 & 0.735 \\
\hline
\end{tabular}

This study tested if there exist a significant relationship between the level of multiple intelligences, profile and the academic performance of the higher degree students of University of Ibadan using chi-square at 0.05 level of significance. Table 3 shows that level of logical $(8.143<0.05)$ and intrapersonal $(19.252<0.05)$ intelligences are related to academic performance. Linguistic intelligence is dependent on age $(16.954<0.05)$. Every other level of intelligence is not related to academic performance. However, generally, the age of the respondents has no bearing on the level of multiple intelligences except linguistic intelligence. From the table, it could also be seen that there is no relationship between gender and level of logical-mathematical, visual, bodily-kinesthetic, musical, interpersonal, intrapersonal, naturalistic and linguistic which are shown by the $\boldsymbol{\varkappa}^{2}$ of $1.094,3.394,4.362,6.328,4.276,2.908,2.700$ and 3.916 respectively. The results showed that all the levels are higher than the set probabilities of 0.05 signifying no significant relationship with academic performance. Furthermore, visual, bodily-kinesthetic, musical, interpersonal, naturalistic and linguistic has no significance relationship with academic performance the data is analyzed using chi-square test Each of the computed $\boldsymbol{\mathcal { X }}^{2}$ have probabilities $>0.05$. This implies that all except logical and intrapersonal level of intelligences has no bearing on academic performance. 
Investigation of Relationship Between Multiple Intelligences of Higher Degree Students on Academic Performance in The University of Ibadan

Table 4: Correlation matrix of multiple intelligences and academic performance

\begin{tabular}{|l|l|l|l|l|l|l|l|l|}
\hline & Lin & Logical & Visual & Bodily & Musical & Inter Intra & Natural & AP \\
\hline Linguistic & .30 & & & & & & & \\
\hline Logical & .39 & .45 & & & & & & \\
\hline Visual & .38 & .48 & .41 & & & & & \\
\hline Bodily-Kinesthetic & .30 & .37 & .27 & .30 & & & & \\
\hline Musical & .45 & .38 & .39 & .32 & .32 & & & \\
\hline Interpersonal & .26 & .29 & .34 & .30 & .22 & .29 & & \\
\hline Intrapersonal & .23 & .24 & .29 & .35 & .24 & .25 & & \\
\hline Natural & .57 & .60 & .40 & .25 & .15 & .42 & & \\
\hline Academic Performance & .61 & .72 & .25 & .20 & -.25 & .35 & .22 & .65 \\
\hline
\end{tabular}

Table 4 indicates the results of Inter scale correlation of the subscales of multiple Intelligence and academic performance. From this table it can be seen that academic performance has high correlation with Logical .72 and Linguistic .61; average correlation with Interpersonal. 46, and low correlation with intrapersonal .30, Spatial .25, Bodily .20, Natural .22, Musical -.25 respectively. On the basis of the inter correlations, it can be concluded that there is a positive correlation between multiple intelligences and academic achievement.

\section{DISCUSSION}

This study had examined the relationship between multiple intelligences and academic performance of higher degree students in the University of Ibadan. The result presented shows that more female than male participated in the study. This result is in agreement with Pérez, Lescano, Heredia, Zalazar, Furlan, and Martínez, (2011) in their study of relationship between multiple intelligences, motor competence and academic achievement where there are more female than male but not in agreement with the study of Rivera (2010) where male were predominant. The result of this study is in tandem with the result of Islam (2015) where logical-mathematical, visual and intrapersonal intelligences were the predominant intelligences of high achiever students. It also support the findings of Ahvan and Pour (2016) revealed that logical-mathematical, visual-spatial, verbal-linguistic, intrapersonal intelligences has positive relationship with test scores but did not in agreement with the findings of Kandeel (2016) that showed no specific intelligence for higher achievers.

Furthermore, the study supports Muthusami (2013) who opined that a positive relationship exists between multiple intelligence and academic achievement. In addition, it also supports the findings of Saadatmanesh (2014) that showed relationship between the students 'combination of multiple intelligences and their final English achievement scores. However, the result of this study disagrees with the result of Hajhashemi (2012) that submitted no significant relationship between the two variables of multiple intelligences and reading scores of the students. This study had also shown that there is higher mean score between multiple intelligences and academic achievement in support of the findings of Mojgan, Zeraatian, Hosseini, Naseripour, and Pazooki (2018). Similarly, it was evident in the result that logical and intrapersonal intelligences were correlated with academic performance whereas the remaining six does not in support of Batulayan (2001) submission in his study of 310 sixth grade pupils in Northern Luzon Mission.

\section{CONCLUSION AND RECOMMENDATION}

The study provided evidence that the logical and linguistic intelligences are the student's most frequent intelligence and the musical intelligence is the students' least frequent intelligence. This could be due to the opportunities and environment that is available in which students are exposed to for the nourishment of intelligence. It is quite possible that logical and linguistic intelligences might have been developed due to the environment available to the learner, and musical and other intelligences might have remained underdeveloped or moderately developed because encouraging environment was not available to them. This study also demonstrated very much high intelligence in Logical-mathematical, interpersonal and visual intelligences but only average in bodily- 
kinesthetic and intrapersonal intelligences. The study had also shown that there is positive relationship between multiple intelligences and academic performance. Results of the study had provided opportunity for lecturers to become aware of the level of intelligence of their students so that they can be better guided to assist them to improve academic performance. This study also helps the parents to understand various levels and dimensions of intelligence in the children for the improvement of academic performance. This result also assists students to discover the weak areas of their intelligences to enable them work hard in that dimension to enhance their academic performance. In view of this result, it is recommended that researchers and lecturers should design teaching strategies that will accommodate multiple intelligences for improve academic performance.

\section{SOURCES OF FUNDING}

None.

\section{CONFLICT OF INTEREST}

None.

\section{ACKNOWLEDGMENT}

None.

\section{REFERENCES}

[1] Dobiszewska M., Pichor W and Szoldra P. (2019): Effect of Basalt powder addition on properties of mortar. MATEC WEB of Conference, 262.

[2] Kasim M., Soram M., Dia E.N and Safia M.O (2017). Effect of aggregate properties on the mechanical and absoption characteristics of geopolymer mortar. Engineering science and Technology, an international Journal, 20(16):1642-1652.

[3] Kumar Y.Y., Vardhan C.M.V and Anitha A. (2015). Use of granite waste as partial substitute to cement in concrete. International Journal of Engineering Research and Application 5(4):25-31

[4] Krzysztof O., Lukasz S., Damian S., Daniel W., Tomasz G., Konrad O and Ireneusz U. (2018). Effect of the morphology of coarse aggregate on the properties of self-compacting high-performance Fibre-reinforced concrete. Material., 11(8): 1372

[5] Mehdi M., Payam S and Muhammad A (2018). The optimum oil palm shell content as coarse aggregate in concrete based on mechanical and durability properties. Advances in Material Sciences and Engineering.

[6] IS: 456 - 2000 (Fourth Revision) Indian Standard Plain and Reinforced Concrete Code of Practice.

[7] IS: 10262-2009 (first revision), Concrete Mix Proportioning Guidelines.

[8] IS: 383-1970 (Second Revision), Specifications for Coarse and Fine Aggregates from Natural Resources for Concrete.

[9] Ramakanta S., Byung J.S., Ji S.I. and Chul W.L (2012). A review of recent advances in catalytic hydrocracking of heavy residues. Journal of Industrial and Engineering Chemistry, 27: 12-24

[10] Sobera G. and Jose V., Relationship between gas adsorption and the shrinkage and creep of recycled aggregate concrete, Cement, Concrete \& Aggregates 25 (2) (2003). 